\title{
Nurse Satisfaction and the Implementation of Minimum Nurse Staffing Regulations
}

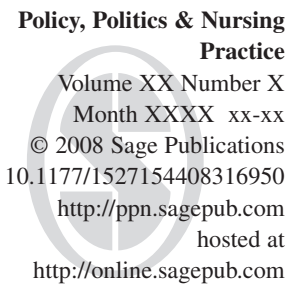

\author{
Joanne Spetz, $\mathrm{PhD}$ \\ University of California, San Francisco
}

\begin{abstract}
In 1999, California passed the first legislation in the United States to establish minimum staffing levels for licensed nurses in hospitals. Implementation of the regulation began in 2004. This article examines whether nurses who work in hospitals in California have perceived improvements in their working conditions. A statewide sample survey of registered nurses is used, and the survey data are linked with regional data to learn whether changes in satisfaction are associated with the degree to which regional employers were expected to increase nurse staffing when the ratios were implemented. Nurse satisfaction improved between 2004 and 2006, particularly with the adequacy of RN staff, time for patient education, benefits, and clerical support. There was a significant increase in overall job satisfaction between 2004 and 2006. However, improvements in satisfaction with the adequacy of RN staff were not associated with the degree to which regional hospitals were expected to increase staffing.
\end{abstract}

Keywords: state legislation; nursing workforce; hospitals; job satisfaction

$\mathrm{I}^{\mathrm{n}}$ 1999, the California legislature passed Assembly Bill 394, which was the first legislation in the United States to establish minimum staffing levels for licensed nurses working in hospitals. This law required the California Department of Health Services to determine the minimum ratios for each type of care unit in hospitals. The specific ratios were announced in 2002 and implemented beginning in 2004.

Assembly Bill 394 arose from concerns about the effects of changes in nurse staffing in the 1990s, with the stated goal of the legislation being to improve the quality of care for hospitalized patients (California Secretary of State, 1999; Spetz, Seago, Coffman, Rosenoff, \& O'Neil, 2000). Nurse staffing is known to be an important contributor to good patient outcomes (e.g., Lang, Hodge, Olson, Romano, \& Kravitz, 2004), but staffing ratios are not the only important factor. The expertise of nursing staff, good nurse-physician communication, and availability of supportive personnel and other health professionals also affect quality of care (e.g., Aiken, Clarke, \& Sloane, 2002; Aiken, Havens, \& Sloane, 2000; Beech, 1995; Dugan et al., 1996).

The minimum staffing ratios were implemented in the midst of a severe national and statewide shortage of registered nurses (RNs; Coffman, Spetz, Seago, Rosenoff, \& O'Neil, 2001). Some proponents of the ratios believe that improved working conditions resulting from the ratios will draw larger numbers of nurses to the hospital workforce (DeMoro, 2001). If this is true, then it might be easier for hospitals to meet the ratio requirements because the supply of RNs will increase. Recent data indicate that the full-time equivalent number of RNs living and working in California has grown more rapidly than anticipated, but it is not known why (Spetz, 2007).

Whether the ratios have a positive effect on working conditions largely depends on hospital compliance with the regulation. One study has documented that licensed nurse staffing in hospitals increased after the implementation of the minimum nurse-to-patient ratios (Donaldson et al., 2005), although it has been reported that only $30 \%$ of hospitals inspected for regular licensing review in the first 10 months of 2004 were in compliance with the ratios (Chong, 2005). Anecdotal evidence and limited data suggest that some hospitals have eliminated support staff positions because of the minimum staffing requirements, perhaps limiting the potential for improvements in workload for licensed nurses (Donaldson et al., 2005; Spetz, 2004, 2006).

This article examines whether nurses who work in hospitals in California have perceived improvements in their working conditions-specifically, whether they

Author's Note: Please address correspondence to Joanne Spetz, 3333 California Street, Suite 410, San Francisco, CA 94118; e-mail: jojo@alum.mit.edu 
were more satisfied with staffing levels and other job attributes in 2006 than in 2004. A statewide sample survey of registered nurses is used for the analysis, and the survey data are linked with regional data to learn whether changes in satisfaction are associated with the degree to which regional employers were expected to increase nurse staffing when the ratios were implemented. The data demonstrate that nurse satisfaction improved between 2004 and 2006, particularly with the adequacy of RN staff, time for patient education, benefits, and clerical support. There was a significant increase in overall job satisfaction between 2004 and 2006. Higher satisfaction with the adequacy of RN staff and clerical support was not the result of changes in the demographic or employment characteristics of nurses. However, improvements in satisfaction with the adequacy of RN staff were not associated with the degree to which regional hospitals were expected to increase staffing.

\section{Data and Method}

This analysis focuses on two surveys conducted by the California Board of Registered Nursing in 2004 and 2006. The purpose of the surveys was to collect and evaluate nursing workforce data to understand the demographics of the nursing workforce, education of the workforce, employment patterns of RNs, nurse perceptions of the work environment, reasons for discontinuing work in nursing, and RN plans for future employment. The 2004 survey was mailed in January, just as the staffing ratios were first being implemented. In March 2005 , the ratios were changed in medical-surgical units to require fewer patients per nurse. ${ }^{1}$ The 2006 survey was mailed in October.

The surveys were sent to randomly selected samples of registered nurses. ${ }^{2}$ The 2004 survey was mailed to a random sample of 8,796 RNs, which included 1,143 RNs living outside of California. This survey yielded 5,168 responses. The 2006 survey was mailed to a stratified random sample of 9,000 RNs, with stratification based on region of California residence. The regions were northern counties, Sacramento region, central fivecounty San Francisco Bay Area, remainder of San Francisco Bay Area, central valley and Sierra, central coast, Los Angeles, inland empire, and border counties (Spetz, Keane, \& Hailer, 2007). The regions were adapted from those developed by the California Economic Strategy Panel (2006). A higher share of RNs was sampled in the northern counties, the Sacramento region, and the central coast to provide adequate data to describe the populations in these regions. Nurses in the San Francisco Bay Area were oversampled with support from the Gordon and Betty Moore Foundation to facilitate their evaluation of their nursing programs. The 2006 survey provided 5,066 responses, which were weighted to represent the statewide population of RNs.

The survey questionnaires included a variety of questions about employment, education, and demographics. Table 1 presents unweighted descriptive statistics for the sample. In 2004, 2,057 RNs working in hospitals were included in the analysis; there were 2,247 RNs from the 2006 survey. Hospital-employed RNs in the sample were slightly older in 2006 and were more likely to have a $\mathrm{BSN}$ or higher degree. A smaller share of respondents in 2006 were employed as staff nurses than in 2004, and hospital-employed RNs averaged slightly fewer hours per week of work in 2006 than in 2004. Nurses in the 2006 sample were more likely to be married and to have children under 13 years old at home. These nurses were also more likely to be male and White.

The first page of each of the questionnaires was a set of items on which respondents were asked to rate their satisfaction on a 5-point Likert-type scale. Most questionnaire items were unchanged between 2004 and 2006. The survey items that were consistent for these two surveys were matched to examine changes in the satisfaction of RNs.

The survey data were analyzed three ways. First, $t$ tests were conducted to determine whether changes in average satisfaction scores were statistically important. Second, multivariate regression equations were estimated to control for the nurse characteristics presented in Table 1 that might be different across the 2004 and 2006 samples and that might also affect nurse satisfaction.

Finally, a variable was added to the regression equations that measures the degree to which hospitals were staffing below the required levels before 2004, as estimated using hospital staffing data from the California Office of Statewide Health Planning and Development (Spetz et al., 2000). The Office of Statewide Health Planning and Development Annual Disclosure Reports provided the number of productive hours worked by RNs and licensed vocational nurses (LVNs, who are equivalent to licensed practical nurses) in each type of care unit, as well as the number of patient days. Productive hours are the number of hours worked by nurses, excluding vacation and other leave. The number of RN and LVN hours a hospital should have staffed in the 1999-2000 fiscal year, had the regulations been in place, is estimated as

$$
\begin{aligned}
& \text { Required }(\mathrm{RN}+\mathrm{LVN}) \text { hours }=(\text { Patient hours }) / \\
& \text { (Maximum patients per nurse })
\end{aligned}
$$

Patient hours are estimated as

Patient hours $=$ patient days $\times 24 \times 1.1$. 
Table 1

Descriptive Statistics for 2004 and 2006 Survey Respondents (Unweighted)

\begin{tabular}{|c|c|c|c|c|}
\hline \multirow[b]{2}{*}{ Variable } & \multicolumn{2}{|c|}{2004} & \multicolumn{2}{|c|}{2006} \\
\hline & $M$ or $\%$ & $S D$ & $M$ or $\%$ & $S D$ \\
\hline Age $(M)$ & 45.51 & 10.37 & 46.49 & 10.57 \\
\hline \multicolumn{5}{|l|}{ Highest education (\%) } \\
\hline Diploma & 12.4 & & 11.1 & \\
\hline $\mathrm{AD}$ & 42.0 & & 40.2 & \\
\hline BSN & 38.9 & & 40.7 & \\
\hline MSN or higher & 6.7 & & 8.0 & \\
\hline Staff nurse (\%) & 80.4 & & 72.1 & \\
\hline Hours per week $(M)$ & 35.87 & 11.44 & 34.67 & 10.64 \\
\hline Nursing income $(\$ ; M)$ & $62,562.99$ & $25,871.55$ & $71,657.86$ & $34,545.95$ \\
\hline Household income $(\$ ; M)$ & $91,920.76$ & $37,263.75$ & $110,106.80$ & $48,602.40$ \\
\hline \multicolumn{5}{|l|}{ Marital status (\%) } \\
\hline Never married & 15.7 & & 12.1 & \\
\hline Married/domestic partner & 66.0 & & 69.9 & \\
\hline Separated/divorced & 16.1 & & 15.6 & \\
\hline Widowed & 2.2 & & 2.4 & \\
\hline Children under 13 at home & 14.8 & & 32.4 & \\
\hline Adult dependents at home & 24.1 & & 24.5 & \\
\hline Female $(\%)$ & 91.2 & & 89.7 & \\
\hline \multicolumn{5}{|l|}{ Race/ethnicity (\%) } \\
\hline White & 60.3 & & 67.7 & \\
\hline Latino & 6.1 & & 6.0 & \\
\hline African American/Black & 3.6 & & 3.9 & \\
\hline Filipino & 19.2 & & 16.4 & \\
\hline Other Asian & 6.4 & & 6.0 & \\
\hline Other race/ethnicity & 4.4 & & 3.7 & \\
\hline Number of observations & 2,057 & & 2,247 & \\
\hline
\end{tabular}

Multiplying by 1.1 adjusts the estimate in accordance with research that found that patient days are, on average, about $10 \%$ longer than 24 hours-that is, 26.4 hours (Unruh, Fottler, \& Talbott, 2003). Note that this adjustment does not change the general assessment of which hospitals had richer staffing.

The estimate of the number of RN and LVN hours that would have been required by the staffing regulations is compared with actual staffing to measure the degree of shortfall:

\section{Shortfall $=($ Actual $\mathrm{RN}+\mathrm{LVN}$ hours - required $\mathrm{RN}+$ LVN hours) / (required RN + LVN hours).}

The estimate of the number of required nurse hours is likely to be lower than it should be because the productive nursing hours reported by hospitals are not limited to direct patient care (Spetz, Donaldson, Aydin, \& Brown, in press). Productive hours, for example, might include charge nurse duties, which would not count as part of the minimum nurse-to-patient ratio requirement. Thus, a greater number of productive hours are needed to meet the staffing requirements. However, this estimate will be highly correlated with the degree to which hospitals would have been expected to increase staffing to meet the staffing regulations.

It is not possible to link individual survey respondents with specific hospitals. Thus, the estimates of the degree of shortfall were averaged for each of the regions in California and matched to survey respondents by region of residence. ${ }^{3}$ Changes in satisfaction among nurses are then compared with the degree to which staffing should have increased in that region. Regional staffing changes may not reflect the experiences of individual nurses; however, previous research has documented significant differences in nurse staffing - and expected nurse hiringbefore the implementation of the minimum staffing regulations (Spetz et al., 2000).

\section{Results}

Table 2 presents satisfaction scores in 2004 and 2006 and the results of $t$ tests of whether the average satisfaction scores for 2004 and 2006 were equivalent. Nurse 
Table 2

Changes in Satisfaction Scores Between 2004 and 2006

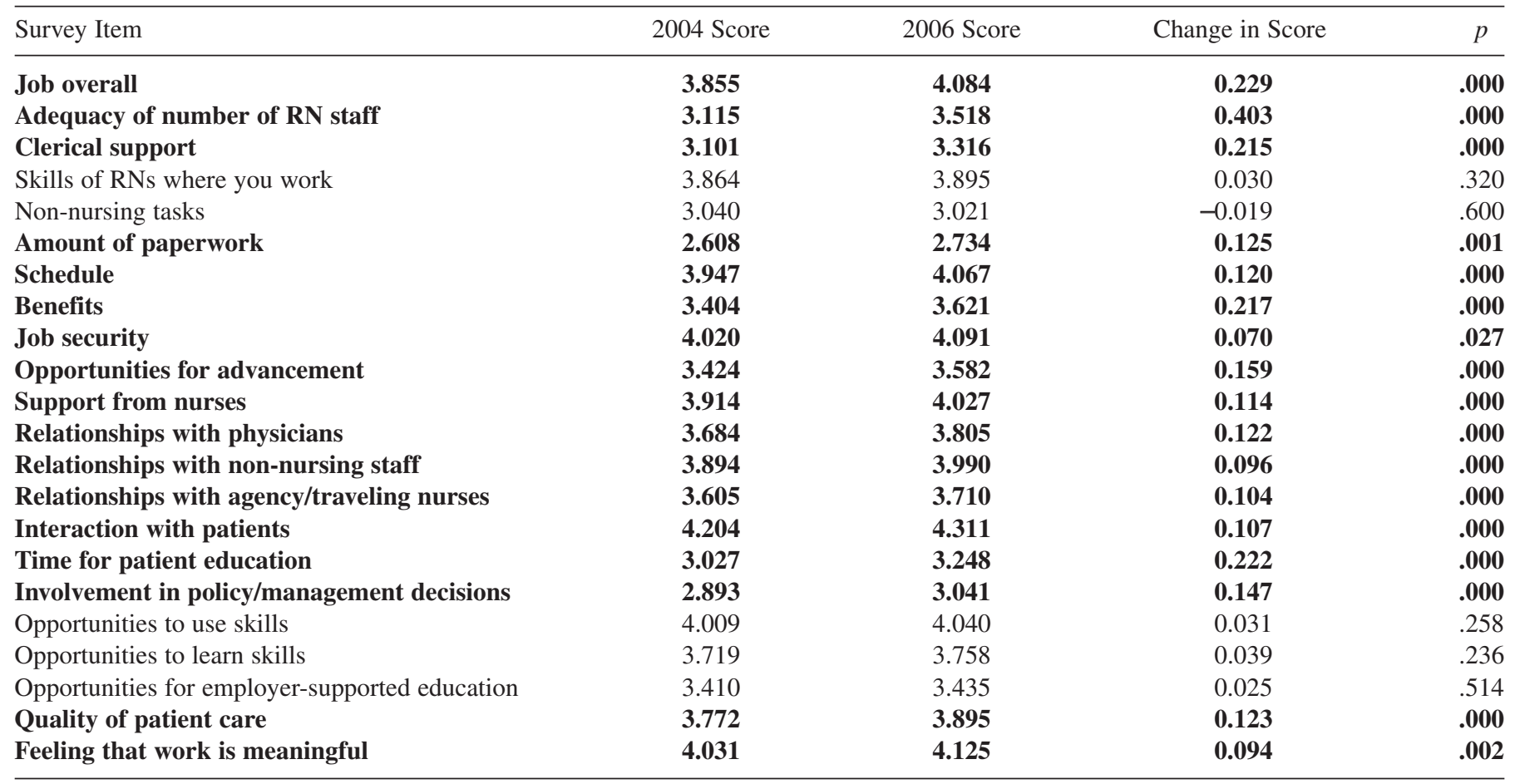

Note: Items with statistically significant changes between 2004 and $2006(p \leq .05)$ are in bold.

satisfaction was rated on a 5-point Likert-type scale, with $1=$ very dissatisfied, $2=$ dissatisfied, $3=$ neither satisfied nor unsatisfied, $4=$ satisfied, and $5=$ very satisfied. Average nurse satisfaction improved with most survey items, including their overall rating of their job. Average satisfaction scores increased the largest number of points for the adequacy of staff ( 0.403 points, from 3.115 to 3.518 ), job overall (0.229 points, from 3.855 to 4.084 ), time for patient education ( 0.221 points, from 3.027 to 3.248 ), benefits ( 0.217 points, from 3.404 to 3.621 ), and clerical support ( 0.215 points, from 3.101 to 3.316 ). The largest changes in satisfaction, in percentage terms, were with adequacy of staff $(12.95 \%)$, time for patient education $(7.33 \%)$, clerical support $(6.92 \%)$, benefits $(6.39 \%)$, and job overall (5.9\%). There was no change in satisfaction with the skills of other RNs, non-nursing tasks, opportunities to learn and use skills, and employer-supported educational opportunities.

The changes in satisfaction observed between 2004 and 2006 may have resulted from changes in the population of RNs, which could also affect satisfaction. To control for this possibility, multivariate ordinary least squares regression equations were estimated, with standard errors clustered by region. The explanatory variables in these equations included age and age-squared, marital status, presence of children or adult dependents in the home, highest RN education, gender, race/ethnicity, hours worked per week, job title of staff nurse, income from nursing, and total household income. The results of these equations are presented in Table 3.

Nurse satisfaction with many aspects of work increased significantly between 2004 and 2006, controlling for demographic, job, and family characteristics. The largest improvements in satisfaction were with adequacy of staff (0.334 points) and clerical support ( 0.207 points). Satisfaction with the amount of paperwork, benefits, relationships with agency/traveling nurses, and time for patient education increased by at least 0.1 points in 2006. These findings indicate that improvements in nurse satisfaction between 2004 and 2006 cannot be attributed solely to changes in nurse demographic, job, and family characteristics.

Table 4 presents the results of ordinary least squares equations to which degree of shortfall is added to measure the percentage by which regional hospitals are estimated to have been below the staffing requirements. A higher number indicates that there should have been greater staffing increases in the region. There is little 
Table 3

Changes in Satisfaction Between 2004 and 2006, From Ordinary Least Squares Regression Equations That Control for Nurse Demographic, Job, and Family Characteristics

\begin{tabular}{lcc}
\hline Survey Item & Change in 2006 & $p$ \\
\hline Job overall & $\mathbf{0 . 1 5 4}$ & $\mathbf{. 0 0 4}$ \\
Adequacy of number of RN staff & $\mathbf{0 . 3 3 4}$ & $\mathbf{. 0 0 0}$ \\
Clerical support & $\mathbf{0 . 2 0 7}$ & $\mathbf{. 0 0 0}$ \\
Skills of RNs where you work & 0.036 & .354 \\
Non-nursing tasks & -0.036 & .494 \\
Amount of paperwork & $\mathbf{0 . 1 1 4}$ & $\mathbf{. 0 5 0}$ \\
Schedule & 0.041 & .388 \\
Benefits & $\mathbf{0 . 1 7 2}$ & $\mathbf{. 0 0 2}$ \\
Job security & 0.021 & .614 \\
Opportunities for advancement & 0.087 & .066 \\
Support from nurses & $\mathbf{0 . 0 7 8}$ & $\mathbf{. 0 2 5}$ \\
Relationships with physicians & 0.048 & .197 \\
Relationships with non-nursing staff & $\mathbf{0 . 0 6 6}$ & $\mathbf{. 0 0 9}$ \\
Relationships with agency/ & $\mathbf{0 . 1 5 4}$ & $\mathbf{. 0 0 0}$ \\
$\quad$ traveling nurses & & \\
Interaction with patients & $\mathbf{0 . 0 8 4}$ & $\mathbf{. 0 1 0}$ \\
Time for patient education & $\mathbf{0 . 1 7 4}$ & $\mathbf{. 0 0 7}$ \\
Involvement in policy/management & 0.041 & .212 \\
$\quad$ decisions & & \\
Opportunities to use skills & -0.030 & .445 \\
Opportunities to learn skills & -0.007 & .865 \\
Opportunities for employer- & -0.027 & .676 \\
supported education & & \\
Quality of patient care & 0.063 & .174 \\
Feeling that work is meaningful & 0.035 & .334 \\
\hline Note: Ite & & \\
\hline
\end{tabular}

Note: Items with a statistically significant coefficient for $2006(p \leq .05)$ are in bold.

indication that nurses who live in regions in which the ratios were anticipated to have the greatest impact experienced greater increases in satisfaction than other nurses. In these equations, few of the coefficients for the 2006 indicators are statistically significant, and only two of the shortfall coefficients are significant. A statistically significant increase in satisfaction with the adequacy of staff between 2004 and 2006 persists, but this increase is not related to the degree of shortfall. Nurse satisfaction with benefits and interactions with patients also increased between 2004 and 2006. Nurses were more satisfied with their relationships with agency or traveling nurses and interactions with patients in 2006, but this improvement was dampened among nurses who lived in regions with a greater degree of shortfall. There was improvement in satisfaction with involvement in policy or management decisions as the degree of shortfall increased.

The lack of statistically significant relationships between degree of regional staffing shortfall and change in satisfaction may result from three phenomena: (a) Nurse
Table 4

Changes in Satisfaction Between 2004 and 2006, by Degree to Which Regional Hospitals

Were Expected to Increase Staffing, From Ordinary Least Squares Regression Equations That Control for Nurse Demographic, Job, and Family Characteristics

\begin{tabular}{lcc}
\hline Survey Item & $\begin{array}{c}\text { Change in } \\
2006\end{array}$ & $\begin{array}{c}\text { Degree of } \\
\text { Shortfall Effect }\end{array}$ \\
\hline Job overall & 0.099 & 0.010 \\
Adequacy of number of RN staff & $0.313^{*}$ & 0.004 \\
Clerical support & 0.092 & 0.020 \\
Skills of RNs where you work & 0.016 & 0.003 \\
Non-nursing tasks & -0.163 & 0.022 \\
Amount of paperwork & 0.028 & 0.015 \\
Schedule & 0.027 & 0.002 \\
Benefits & $0.337^{*}$ & -0.029 \\
Job security & 0.033 & -0.002 \\
Opportunities for advancement & 0.026 & 0.011 \\
Support from nurses & 0.024 & 0.009 \\
Relationships with physicians & 0.104 & -0.010 \\
Relationships with non-nursing staff & 0.069 & -0.0004 \\
Relationships with agency/ & $0.280^{*}$ & $-0.022^{*}$ \\
$\quad$ traveling nurses & & \\
Interaction with patients & $0.116^{*}$ & -0.006 \\
Time for patient education & 0.047 & 0.022 \\
Involvement in policy/ & -0.107 & $0.026^{*}$ \\
$\quad$ management decisions & & \\
Opportunities to use skills & -0.056 & 0.004 \\
Opportunities to learn skills & -0.020 & 0.002 \\
Opportunities for employer- & -0.137 & 0.019 \\
$\quad$ supported education & & \\
Quality of patient care & -0.013 & 0.013 \\
Feeling that work is meaningful & 0.003 & 0.006 \\
\hline & &
\end{tabular}

$* p \leq .05$.

satisfaction is associated with hospital-level change in staffing, and regional changes are not closely correlated with specific hospital changes; (b) hospitals did not actually change staffing as much as they should have when the ratios were implemented; or (c) the specific change in staffing does not affect the degree of change in RN satisfaction. The data do not provide enough information to determine which of these possibilities are true.

\section{Limitations}

Several limitations are present in this study. First, survey respondents may not represent all California RNs; this is a common limitation of surveys. Second, the satisfaction items included in the surveys do not specifically ask respondents whether the minimum nurse-to-patient ratio regulations have improved their job satisfaction. It 
is possible that changes in satisfaction arose from factors other than the legislation.

A third and more important limitation is that it is not possible to match survey respondents to specific hospitals, and thus one must assume that the staffing situation each respondent experienced is that of the regional average. Hospital staffing varies substantially within regions; thus, the regional average measures the individual nurses' experiences with error. Such measurement error will bias results toward zero and thus reduce the ability of the analysis to detect significant relationships.

\section{Discussion}

The staffing legislation passed in California was promoted primarily as a means to improve the quality of care for patients by guaranteeing a minimum level of nursing care in acute care hospitals. A secondary goal of the legislation was to improve working conditions for nurses, with the expectation that improved working conditions would improve nurse recruitment and retention in the midst of a severe nurse shortage.

Nursing turnover is known to be high; it has been reported that nursing turnover in hospitals ranges from $15 \%$ to $36 \%$ per year (Hayes et al., 2006). A large body of research links job satisfaction, heavy workload, job stress, effective management, and career development opportunities with turnover rates (Coomber \& Barriball, 2007; Hayes et al., 2006).

The extent to which increased nurse satisfaction can lead to improved recruitment of nurses is unknown. It is possible that licensed nurses who are presently not employed in nursing jobs could be attracted to nursing work as the work environment improves. However, there is no research that definitively demonstrates this process. Researchers have found that advice from practicing nurses is the most influential factor in deciding to become a nurse (Buerhaus, Donelan, Norman, \& Dittus, 2005); thus, if currently employed nurses are more satisfied, they may be more likely to attract new people to the field through personal communications.

At this time, it is not known whether California's regulations have resulted in improvements in the quality of care provided to hospital patients. It is possible that the improvements in RN satisfaction documented here will facilitate higher quality of care. High nurse turnover has a negative effect on the quality of care delivered to patients (Gray \& Phillips, 1996; Tai, Bame, \& Robinson, 1998). If minimum staffing regulations improve nurse satisfaction, reduce job stress, and relieve workload, nurse turnover may indeed decline, further improving the quality of hospital care.
It is encouraging to observe improvements in the satisfaction of RNs, and the potential link between minimum nurse staffing regulations and greater satisfaction is intriguing. Future research should focus on whether nurse turnover and recruitment measurably improved after California's regulation was implemented. More important, careful research should be conducted to learn the effect of the regulations on the quality of care for hospital patients.

\section{Notes}

1. The initial ratio in medical-surgical units was one licensed nurse per six patients. In March 2005, the ratio in medical-surgical units changed to one licensed nurse per five patients. The final implementation of the ratios occurred in January 2008, with changes in step-down, telemetry, and other specialty units.

2. Details about the 2004 survey can be found in Fletcher, Guzley, Barnhill, and Philhour (2004). Details about the 2006 survey can be found in Spetz, Keane, and Hailer. (2007).

3 . The regions used for this analysis are the same as those used in the stratification of the 2006 survey.

\section{References}

Aiken, L. H., Clarke, S. P., \& Sloane, D. M. (2002). Hospital staffing, organization, and quality of care: Cross-national findings. International Journal for Quality in Health Care, 14, 5-13.

Aiken, L. H., Havens, D. S., \& Sloane, D. M. (2000). The Magnet Nursing Services Recognition Program: A comparison of two groups of magnet hospitals. American Journal of Nursing, 100, 26-36.

Beech, B. M. (1995). Patient satisfaction and nursing staff work satisfaction in an urban public teaching hospital. Unpublished doctoral dissertation, University of Texas Health Sciences Center.

Buerhaus, P. I., Donelan, K., Norman, L., \& Dittus, R. (2005). Nursing students' perceptions of a career in nursing and impact of a national campaign designed to attract people into the nursing profession. Journal of Professional Nursing, 21, 75-83.

California Economic Strategy Panel. (2006). California economic strategy panel regions. Sacramento: California Labor Workforce \& Development Agency.

California Secretary of State. (1999). Assembly Bill 394 (Kuehl), chaptered October 10, 1999.

Chong, J.-R. (2005, February 6). Some hospitals met nurse ratios. Los Angeles Times, p. B1.

Coffman, J., Spetz, J., Seago, J. A., Rosenoff, E., \& O’Neil, E. (2001). Nursing in California: A workforce crisis. San Francisco: California Workforce Initiative and the University of California, San Francisco, Center for the Health Professions.

Coomber, B., \& Barriball, K. L. (2007). Impact of job satisfaction components on intent to leave and turnover for hospital-based nurses: A review of the research literature. International Journal of Nursing Studies, 44, 297-314.

DeMoro, R. A. (2001, August 16). Nursing shortage: A demand for action. San Francisco Chronicle, p. A25.

Donaldson, N., Bolton, L. B., Aydin, C., Brown, D., Elashoff, J., \& Sandhu, M. (2005). Impact of California's licensed nurse-patient ratios on unit-level nurse staffing and patient outcomes. Policy, Politics, \& Nursing Practice, 6, 1-12. 
Dugan, J., Lauer, E., Bouquot, Z., Dutro, B. K., Smith, M., \& Widmeyer, G. (1996). Stressful nurses: The effect on patient outcomes. Journal of Nursing Care Quality, 10, 46-58.

Fletcher, J. E., Guzley, R. M., Barnhill, J., \& Philhour, D. (2004). Survey of registered nurses in California, 2004. Sacramento: California Board of Registered Nursing.

Gray, A. M., \& Phillips, V. L. (1996). Labour turnover in the British National Health Service: A local labour market analysis. Health Policy, 36, 273-289.

Hayes, L. J., O’Brien-Pallas, L., Duffield, C., Shamian, J., Buchan, J., Hughes, F., et al. (2006). Nurse turnover: A literature review. International Journal of Nursing Studies, 43, 237-263.

Lang, T. A., Hodge, M., Olson, V., Romano, P. S., \& Kravitz, R. L. (2004). Nurse-patient ratios: A systematic review on the effects of nurse staffing on patient, nurse employee, and hospital outcomes. Journal of Nursing Administration, 34, 326-337.

Spetz, J. (2004). California's minimum nurse-to-patient ratios: The first few months. Journal of Nursing Administration, 34, 571-578.

Spetz, J. (2006). California nursing staff ratios. In D. Mason (Ed.), Policy and politics in nursing and health care (5th ed., pp. 518527). Philadelphia: W. B. Saunders.

Spetz, J. (2007). Forecasts of the registered nurse workforce in California. Sacramento: California Board of Registered Nursing.
Spetz, J., Donaldson, N., Aydin, C., \& Brown, D. (in press). How many nurses per patient? Measurements of nurse staffing in health services research. Health Services Research.

Spetz, J., Keane, D., \& Hailer, L. (2007). 2006 survey of registered nurses. Sacramento: California Board of Registered Nursing.

Spetz, J., Seago, J. A., Coffman, J., Rosenoff, E., \& O’Neil, E. (2000). Minimum nurse staffing ratios in California acute care hospitals. San Francisco: California HealthCare Foundation.

Tai, T. W. C., Bame, S. I., \& Robinson, C. D. (1998). Review of nursing turnover research, 1977-1996. Social Science and Medicine, 47, 1905-1924.

Unruh, L. Y., Fottler, M. D., \& Talbott, L. L. (2003). Improving nurse staffing measures: Discharge day measurement in adjusted patient days of care. Inquiry, 40, 295-304.

Joanne Spetz, PhD, is an associate professor in the Departments of Community Health Systems and Social and Behavioral Sciences at the University of California, San Francisco (UCSF). She works at the UCSF Center for the Health Professions on studies of the nursing workforce, hospital industry, and health information technology. 